\title{
A novel adsorbent features like EDTA synthesized in situ by chemically modified cellulose and its behavior in metal ions adsorption from aqueous solution
}

\section{$\mathrm{Tao} \mathrm{Hu}$}

Sichuan University of Arts and Science

Xiaoli Hu (D 441430968@qq.com)

Sichuan University of Arts and Science https://orcid.org/0000-0003-2841-0151

Cheng Tang

Sichuan University of Arts and Science

Dan Liu

Sichuan University of Arts and Science

\section{Research Article}

Keywords: Modified cellulose, Aminoacetic acid group, Adsorption, Metal ions

Posted Date: July 15th, 2021

DOl: https://doi.org/10.21203/rs.3.rs-716496/v1

License: (c) (i) This work is licensed under a Creative Commons Attribution 4.0 International License.

Read Full License 


\title{
A novel adsorbent features like EDTA synthesized in situ by
} chemically modified cellulose and its behavior in metal ions

\section{adsorption from aqueous solution}

\author{
Tao $\mathrm{Hu} \cdot$ Xiaoli $\mathrm{Hu} \cdot$ Cheng Tang $\cdot$ Dan Liu
}

\begin{abstract}
This paper describes the synthesis of a novel chelating material derived from cellulose, and its heavy metal ions adsorption behavior from aqueous solution. The first section of this paper reports the chemical grafting of cellulose, that aminoacetic acid groups were grafted into the cellulose, resulted a novel yet unreported modified cellulose derivative $\mathrm{N}, \mathrm{N}$-(dicarboxymethylaminoethyl, carboxymethyl) aminoethylamine carboxymethyl cellulose amide. This obtained adsorbent was characterized by elemental analysis, infrared spectroscopy (IR) and Solid State Nuclear Magnetic Resonance (SSNMR) ${ }^{13} \mathrm{C}$ NMR spectroscopy. In the second section, adsorption behaviors such as kinetic study, adsorption isotherms of the adsorbent for $\mathrm{Cu}^{2+}$ and $\mathrm{Pb}^{2+}$ single metal ions from aqueous solution, and adsorption capacity for $\mathrm{Ba}^{2+}, \mathrm{Mg}^{2+}, \mathrm{Mn}^{2+}, \mathrm{Co}^{2+}, \mathrm{Zn}^{2+}, \mathrm{Pb}^{2+}, \mathrm{Ni}^{2+}$ and $\mathrm{Cu}^{2+}$, and the competitive adsorption of this adsorbent between ions were evaluated by ICP spectroscopy.
\end{abstract}

Keywords Modified cellulose $\cdot$ Aminoacetic acid group $\cdot$ Adsorption $\cdot$ Metal ions

\section{Introduction}

Environmental problems is always one of the focus that people concerned about. Heavy metal pollution accounts for a large proportion of all pollutant species, as a main pollution source, heavy metal ion pollution in water is related to everyone's health. For example, $\mathrm{Cu}^{2+}, \mathrm{Hg}^{2+}, \mathrm{Ag}^{+}$and other trace amounts of heavy metals enter

T. Hu $\cdot$ X. Hu $(\bowtie) \cdot$ C. Tang $\cdot$ D. Liu Chemistry and Chemical Engineering School, Sichuan University of Arts and Sciences, Dazhou Sichuan 635000, People`s Republic of China e-mail: 441430968@qq.com

T. $\mathrm{Hu}$

Eastern Sichuan Sub-center of National Engineering Research Center for Municipal Waste water Treatment and Reuse, Dazhou Sichuan 635000, People`s Republic of China 
human body through food and drinking water and then enriched, resulting in heavy metal poisoning, caused great harm to human health (Pereira. 2016 and Bhalla et al. 2007). The $\mathrm{Cu}^{2+}$ content in drinking water must not exceed $20 \mathrm{uM}$, the normal concentration of copper ions in blood is 15.7-23.6 uM (100-150ug/dL) (Mi et al. 2007; Carver. 2013 and Kirsipuu et al. 2020). Therefore, heavy metal ions removal from water with low cost and high efficiency has been a hot topic.

At present, the removal methods of heavy metal ions mainly include chemical precipitation, electrolysis, ion exchange, reverse osmosis, and membrane separation etc (Hu et al. 2016; Barakat. 2011 and Xu C. 2014 ). Among them, electrolysis and chemical precipitation are not suitable for the treatment of trace heavy metal waste water, ion exchange and membrane separation have better effect on the treatment of trace heavy metal ions, but the treatment capacity is limited and the maintenance cost is relatively high. Therefore, the materials with large adsorption capacity, high selectivity, wide range of source, cheap and renewable have been paid more and more attention in the field of heavy metal removal (Barakat. 2011).

Cellulose is the most abundant natural biomass resource in nature, meets the above conditions. It has a wide range of sources and biodegradability, and there are a large number of easily reactive chemical groups in the molecules, which are widely used in the modified matrix of various metal ion pollutant adsorbents (Ghanshyam. 2005; Hu et al. 2016; Cao et al. 2017; Gao et al. 2018; Nongbe et al. 2018; Lin et al. 2021). Cellulose-based heavy metal ion adsorbents have great potential for the adsorption and removal of heavy metal ions in water because of their good adsorption properties, good mechanical properties and renewable.

Many studies have been published around the world about cellulose chemically modified by esterification with EDTA for metal ion recovery, such as adsorption and removal of $\mathrm{Cu}^{2+} 、 \mathrm{Co}^{2+} 、 \mathrm{Ni}^{2+}$; metal ions in aqueous solution by cellulose EDTA solid phase extractant reported by Satoshi Tsukinoki (Tsukinoki et al. 2008), the preparation of hydrophilic filter paper which can filter and remove heavy metal ions, and the preparation of metal ion adsorption materials which connect EDTA to cellulose derivatives by Issam Jilal (Jilal et al. 2018) and Halluin MD (Halluin et al. 
2017); In other reports (Singh et al. 2012; Huang et al. 2015), EDTA analogues of amino triacetic acid were grafted to cellulose. These materials have good adsorption properties for metal ions.

This work describes the preparation a novel chelating adsorbent by chemically modified cellulose, that aminoacetic acid groups was introduced into cellulose, and the evaluation its adsorbtion heavy metal ions in water. The first section of this work describes the chemically grafting of cellulose by introduced with aminoacetic acid functions. The second section of this work evaluates the conditions of adsorption of $\mathrm{Cu}^{2+}$ and $\mathrm{Pb}^{2+}$ by this grafted cellulose from aqueous solutions, and adsorption capacity for $\mathrm{Ba}^{2+}, \mathrm{Mg}^{2+}, \mathrm{Mn}^{2+}, \mathrm{Co}^{2+}, \mathrm{Zn}^{2+}, \mathrm{Pb}^{2+}, \mathrm{Ni}^{2+}$ and $\mathrm{Cu}^{2+}$, and the competitive adsorption of this adsorbent between ions were also evaluated by ICP spectroscopy.

\section{Experimental}

Materials

Microcrystalline cellulose was purchased from Huzhou Linghu Xinwang Chemical Co., Ltd. Polyamine diethylenetriamine was from Shanghai Aladdin Biochemical Technology Co., Ltd. Chloroacetic acid was bought from Sinopharm Chemical Reagent Co., Ltd. Dichlorosulfoxide $\left(\mathrm{SOCl}_{2}\right)$, methanol, ethanol, N,N-Dimethyl formamide (DMF), $\mathrm{Na}_{2} \mathrm{CO}_{3}$ were purchased from ChengDu Chron Chemicals Co,.Ltd, and were used without further purification.

Synthesis of carboxymethyl cellulose 1

According to literature method (Wilpiszewska et al. 2020; Ardiyanita et al. 2020), the microcrystalline cellulose was suspended in $25 \% \mathrm{NaOH}$ (mass fraction) and etherified with chloroacetic acid at $65^{\circ} \mathrm{C}$. After the reaction completed, a solid particles were obtained by cooling, acidification, filtration and washed with ethanol. 
Synthesis of Methyl carboxymethyl cellulose ester 2

In a $250 \mathrm{~mL}$ bottom flask, $10 \mathrm{~g}$ of carboxymethyl cellulose, $100 \mathrm{~mL}$ anhydrous methanol, $1 \mathrm{~mL}$ DMF were added, cooled by ice bath, with magnetic stirring, $12 \mathrm{~mL}$ of $\mathrm{SOCl}_{2}$ was added slowly with a drop funnel and reaction temperature was controlled below $5^{\circ} \mathrm{C}$. And then the reaction was continued at room temperature for another 24 hours. After reaction complete, a white small granular solid were obtained by Vacuum filtration, washed with anhydrous ethanol until no $\mathrm{HCl}$ was detected, and dried with vacuum.

Synthesis of diethylenetriamine carboxymethyl cellulose amide $\mathbf{3}$

Methyl Carboxymethyl cellulose ester $5 \mathrm{~g}$, anhydrous ethanol $50 \mathrm{~mL}, 5 \mathrm{~mL}(0.0465$ mol) diethylenetriamine were added respectively into a $100 \mathrm{~mL}$ round bottom flask, and sealed in $75{ }^{\circ} \mathrm{C}$ water bath for about 48 hours. After cool to room temperature, filter, washed with anhydrous ethanol to neutral, dried, get a white solid, which has weak ammonia smell.

Synthesis of N,N-(dicarboxymethylaminoethyl, carboxymethyl) aminoethylamine carboxymethyl cellulose amide $\mathbf{4}$

$9.0 \mathrm{~g}$ chloroacetic acid (about $0.1 \mathrm{~mol}$ ) was dissolved in $20 \mathrm{~mL}$ distilled water in a $250 \mathrm{~mL}$ round bottom flask, with stirring, $\mathrm{Na}_{2} \mathrm{CO}_{3}$ powder was added to adjust the $\mathrm{pH}$ value to 9-10. And then $100 \mathrm{~mL}$ anhydrous ethanol, 4.9g diethylenetriamine carboxymethyl cellulose amide were added, and the reactant was stirred for 72 hours at room temperature. The $\mathrm{pH}$ value was detected and adjusted with anhydrous $\mathrm{Na}_{2} \mathrm{CO}_{3}$ during the reaction and maintained between 9-10. Stand still, Filter, Washed with ethanol, dried, a white solid was obtained.

\section{Kinetic study of metal ion adsorption of 4}


Adsorption equilibrium time of adsorbent with metal ions was determined within 50 min in several min intervals. $10 \mathrm{mg}$ of adsorbent was placed in a $50 \mathrm{~mL}$ round bottom flask, and then $10.0 \mathrm{~mL}$ of $500 \mathrm{ppm}$ metal ion solution was added with continuous stirring. The absorption process were carried out at $\mathrm{pHs} 5.0$ for $\mathrm{Cu}^{2+}$ and $\mathrm{Pb}^{2+}$, optimal contact time to get the best adsorption. Along with process, $\mathrm{pH}$ values should be adjusted and maintained at 5.0, and $\mathrm{NaOH}$ solution $(0.01 \mathrm{~mol} / \mathrm{L})$ could be added into the solutions. After filtration, the concentration of metal ion remained in aquous solution was determined by ICP spectroscopy.

$\mathrm{pH}$ study of metal ion adsorption of 4

The effect of $\mathrm{pHs}$ on metal ion adsorption were performed by experiments with adsorbent and metal ion $\mathrm{Cu}^{2+}$ and $\mathrm{Pb}^{2+} .10 \mathrm{mg}$ of adsorbent 4 was added into a $50 \mathrm{~mL}$ round bottom flask, and then under continuous stirring $10.0 \mathrm{~mL}$ of $500 \mathrm{ppm}$ metal ion solution was added. $\mathrm{pH}$ was adjusted when needed with $\mathrm{NaOH}$ or $\mathrm{HCl}$ solutions $(0.1-1.0 \mathrm{~mol} / \mathrm{L})$. The contact time in experiments were $30 \mathrm{~min}$. After filtration, the remaining metal ion concentration of the solution was determined by the ICP spectroscopy. No significant change in the $\mathrm{pH}$ values in the solution was observed in the course of experiments.

Saturated adsorption for ions and competitive ions adsorption experiments

According to the conditions obtained from adsorption for $\mathrm{Pb}^{2+}$ and $\mathrm{Cu}^{2+}$, the contact time was 30 minutes, a maximum pHs value before ion hydrolysis was chosen, $\mathrm{pHs}$ 7.0 for $\mathrm{Ba}^{2+}, \mathrm{Mg}^{2+}$ and $\mathrm{Mn}^{2+}$, pHs 6.0 for $\mathrm{Co}^{2+}$ and $\mathrm{Ni}^{2+}, \mathrm{pH} 4.0$ for $\mathrm{Zn}^{2+}$. In the competitive ions adsorption experiments, a lower $\mathrm{pHs}$ of the ion was selected for preventing the hydrolysis of the easily hydrolyzed metal ion, for example, competitive ions adsorption between $\mathrm{Mg}^{2+}$ and $\mathrm{Zn}^{2+}$, $\mathrm{pH} 4.0$ was chosen. Initial concentration of all metal ions was $300 \mathrm{ppm}$. 
Saturated adsorption for ions. $10 \mathrm{mg}$ of adsorbent 4 was added into a $50 \mathrm{~mL}$

round bottom flask, and then under continuous stirring $10.0 \mathrm{~mL}$ of $300 \mathrm{ppm}$ metal ion solution was added. $\mathrm{pH}$ was adjusted when needed with $\mathrm{NaOH}$ or $\mathrm{HCl}$ solutions $(0.1-1.0 \mathrm{~mol} / \mathrm{L})$. The contact time in experiments were $30 \mathrm{~min}$. After filtration, the remaining metal ion concentration of the solution was determined by the ICP spectroscopy.

Competitive ions adsorption. $20 \mathrm{mg}$ of adsorbent $\mathbf{4}$ was added into a $50 \mathrm{~mL}$ round bottom flask, and then under continuous stirring $20.0 \mathrm{~mL}$ of mixed solution (300 ppm metal ion 1 and 300 ppm metal ion 2) was added. $\mathrm{pH}$ was adjusted when needed with $\mathrm{NaOH}$ or $\mathrm{HCl}$ solutions $(0.1-1.0 \mathrm{~mol} / \mathrm{L})$. The contact time in experiments were 30 min. After filtration, the remaining metal ions concentration of the solution were determined by the ICP spectroscopy. No significant change in the $\mathrm{pH}$ values in the solution was observed in the course of experiments.

Characterization for materials obtained

The characterization of materials $\mathbf{1}, \mathbf{2}$ and $\mathbf{3}$ were carried out by IR spectroscopy in a iS10 FT-IR spectrometer from Thermo Nicolet Corporation equipment with KBr. And the terminal adsorbent 4 was characterized by IR spectroscopy, Elemental analyses were accomplished in Vario EL cube from Elementar Trading (shanghai) Co.,Ltd, and Solid State Nuclear Magnetic Resonance (SSNMR) ${ }^{13} \mathrm{C}$ NMR spectroscopy was recorded by a Bruker AVANCE III 600M equipment. Metal ion concentration was determined by ICP spectroscopy with an ICP-OES 5110 spectrometer produced by Agilent Technologies Inc.

\section{Results and discussion}

Synthesis of N,N-(dicarboxymethylaminoethyl, carboxymethyl) aminoethylamine carboxymethyl cellulose amide 4 
The route used to synthesize terminal adsorbent $\mathbf{4}$ was presented in Fig.1.

Carboxymethyl cellulose is the largest production of cellulose ether, the most widely used, and the most convenient product, commonly known as "industrial condiments". Its synthesis method is mature and the product quality is stable. We used the conventional method reported in the literature to synthesize.

The esterification of carboxymethyl cellulose has not been reported in literature. The esterification reaction is a solid and liquid heterogeneous reaction, for a better esterification effect, we use $\mathrm{SOCl}_{2} / \mathrm{DMF} / \mathrm{CH}_{3} \mathrm{OH}$ (Hosangadi et al. 1996) as reagents. And during the procedure, $\mathrm{SOCl}_{2}$ was added very slowly and ice bath was used to keep low temperature. When addition was completed, the reaction was carried out at room temperature to avoid heating, and avoid a large amount of $\mathrm{HCl}$ released in a short time, which will lead to the fracture of cellulose ether bond, and caused the decomposition of cellulose into small molecular products.

Ammonolysis is also a solid and liquid heterogeneous reaction. In order to obtain satisfactory ammonolysis effect, we use a large amount of excess one of the reactants to increase the yield of ammonolysis. The ratio of reaction material is as follows: diethylenetriamine: cellulose structure unit $=1.5: 1$. The reaction system is alkaline and the ether bond does not be broken. The reaction temperature was $75^{\circ} \mathrm{C}$, heating can accelerate the reaction. After the reaction time is for about 48 hours, cooled, filtered by vacuum to remove the unreacted amine, a white solid product obtained, with a faint smell of ammonia.

The terminal product was obtained by carboxymethylation of amino groups with chloroacetic acid under alkaline conditions. The final product was obtained in the form of sodium salt, filtered, dried to obtain small white granular solids.

The intermediate products were identified by infrared spectrum, and the final product was verified by infrared spectrum, elemental analysis and Solid State Nuclear Magnetic Resonance (SSNMR) ${ }^{13} \mathrm{C}$ NMR spectroscopy. 


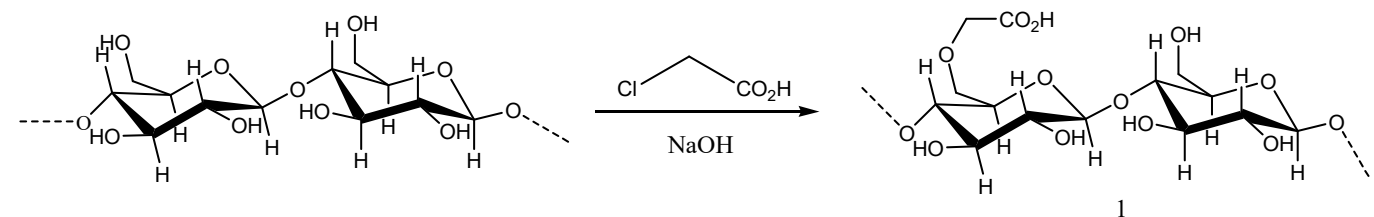

203

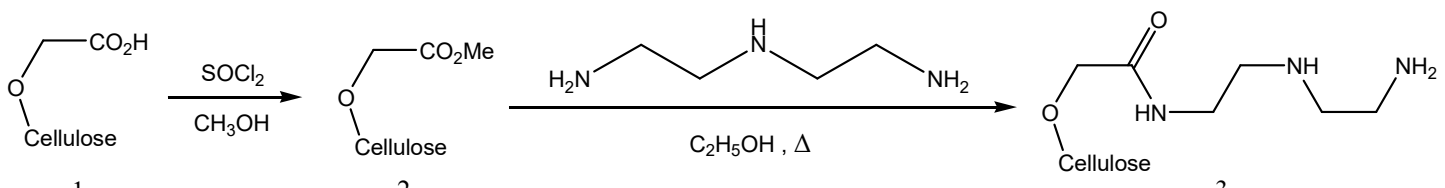

Fig.1. Synthesis route for the terminal adsorbent 4

Carboxymethyl cellulose $\mathbf{1}$ was Characterized by IR spectroscopy. The spectrum of $\mathbf{1}$ and unmodified cellulose was displayed in Fig.2. Compared with unmodified cellulose, a strong band at $1733 \mathrm{~cm}^{-1}$ in $\mathbf{1}$ was found, and it is the evidence that carbonyl functions was introduced into cellulose.

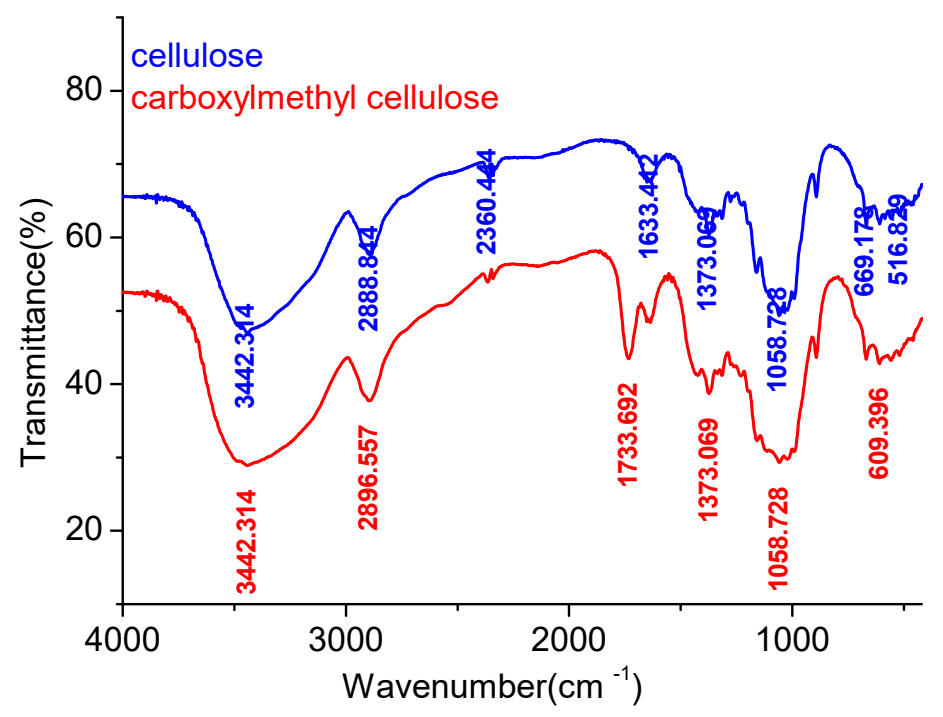

Fig. 2. IR spectrum of cellulose and carboxymethyl cellulose $\mathbf{1}$ 


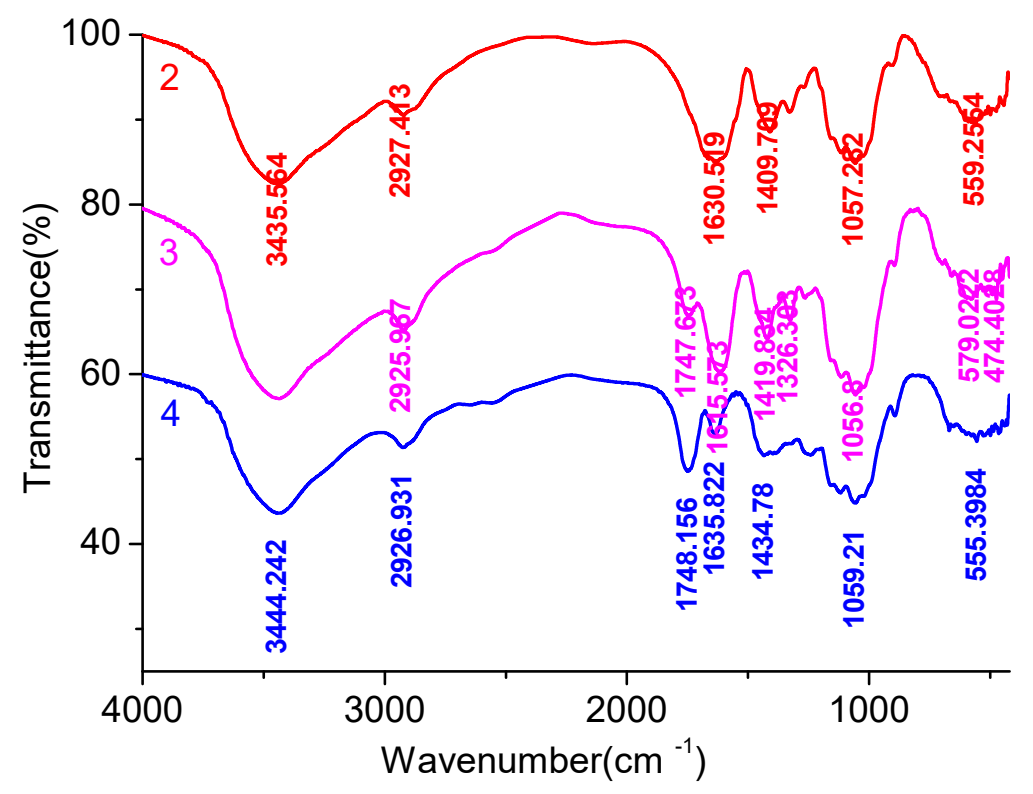

Fig. 3. IR spectrum of $\mathbf{2}, \mathbf{3}$ and $\mathbf{4}$

The IR spectra of 2, 3, and $\mathbf{4}$ showed in Fig.3. Product of esterification of carboxymethyl cellulose 2 showed a very wide and strong new band at $1630 \mathrm{~cm}^{-1}$, Here is the stretching vibration of $\mathrm{C}=\mathrm{O}$ of the carbonyl in ester. Accompanied by the disappearance of $\mathrm{C}=\mathrm{O}$ double bonds stretching vibration in carboxylic acid at 1733 $\mathrm{cm}^{-1}$, indicating the successful esterification.

IR spectrum of Material 3 presented In Fig.3. One band found at $1747 \mathrm{~cm}^{-1}$ was assigned to $\mathrm{C}=\mathrm{O}$ for stretch vibration. A very strong band found at $1615 \mathrm{~cm}^{-1}$ was assigned for the presence of axial deformation vibration of $\mathrm{C}=\mathrm{O}$ in the amide and angular deformation vibration of $\mathrm{N}-\mathrm{H}$ in amine. The band appear at $1419 \mathrm{~cm}^{-1}$ was assigned to $\mathrm{C}-\mathrm{N}$ bond in the amide (Osvaldo et al. 2007).

Terminal material $\mathbf{4}$ was got by carboxymethylation from $\mathbf{3}$, one band found at $1748 \mathrm{~cm}^{-1}$ assigned to $\mathrm{C}=\mathrm{O}$ for stretch vibration is much stronger than material 3 for the increase of acid groups, and bands of axial deformation of $\mathrm{C}=\mathrm{O}$ in the amide and the $\mathrm{N}-\mathrm{H}$ bond angular deformation in amine appears at $1635 \mathrm{~cm}^{-1}$, which became weaker for the substitution of $\mathrm{N}-\mathrm{H}$ by chloroacetic acid. 
Table 1

237

Main IR absorption peaks found in 1, 2, 3 and 4

\begin{tabular}{ll}
\hline materials & Bands found $\left(\mathrm{cm}^{-1}\right)$ \\
\hline $\mathbf{1}$ & $1733,1421,1373,1058$ \\
$\mathbf{2}$ & $1630,1409,1057$ \\
$\mathbf{3}$ & $1747,1615,1419,1326,1058$ \\
$\mathbf{4}$ & $1748,1635,1434,1059$ \\
\hline
\end{tabular}

Solid State Nuclear Magnetic Resonance (SSNMR) ${ }^{13} \mathrm{C}$ NMR spectrum of

239 material 4 was represented in Fig.4, and the chemical shift and its assignments were

$240 \quad$ list in Table 2.

241 Table 2

242 Chemical shift and assignment ${ }^{13} \mathrm{C}$ NMR spectrum of 4

\begin{tabular}{ll}
\hline Chemical shift $(\mathrm{ppm})$ & Assignment \\
\hline 178,171 & $-\underline{\mathrm{CO}} 2 \mathrm{H},-\underline{\mathrm{CON}}-$ \\
103 & $\mathrm{O}-\underline{\mathrm{C}}-\mathrm{O}$ of cellulose \\
$65-85$ & Carbons in cellulose, $\mathrm{O}-\underline{\mathrm{C}} \mathrm{H}_{2}-\mathrm{CON}$ \\
$50-65$ & $\mathrm{~N}-\underline{\mathrm{CH}}_{2}-\underline{\mathrm{CH}}_{2}-\mathrm{N}, \mathrm{CON}-\mathrm{CH}_{2}-\underline{\mathrm{C}} \mathrm{H}_{2}-\mathrm{N}$, \\
& $\mathrm{N}-\underline{\mathrm{C}} \mathrm{H}_{2}-\mathrm{CO}_{2} \mathrm{H}$ \\
36 & $\mathrm{CON}-\underline{\mathrm{CH}_{2}-\mathrm{CH}_{2}-\mathrm{N}}$ \\
\hline
\end{tabular}

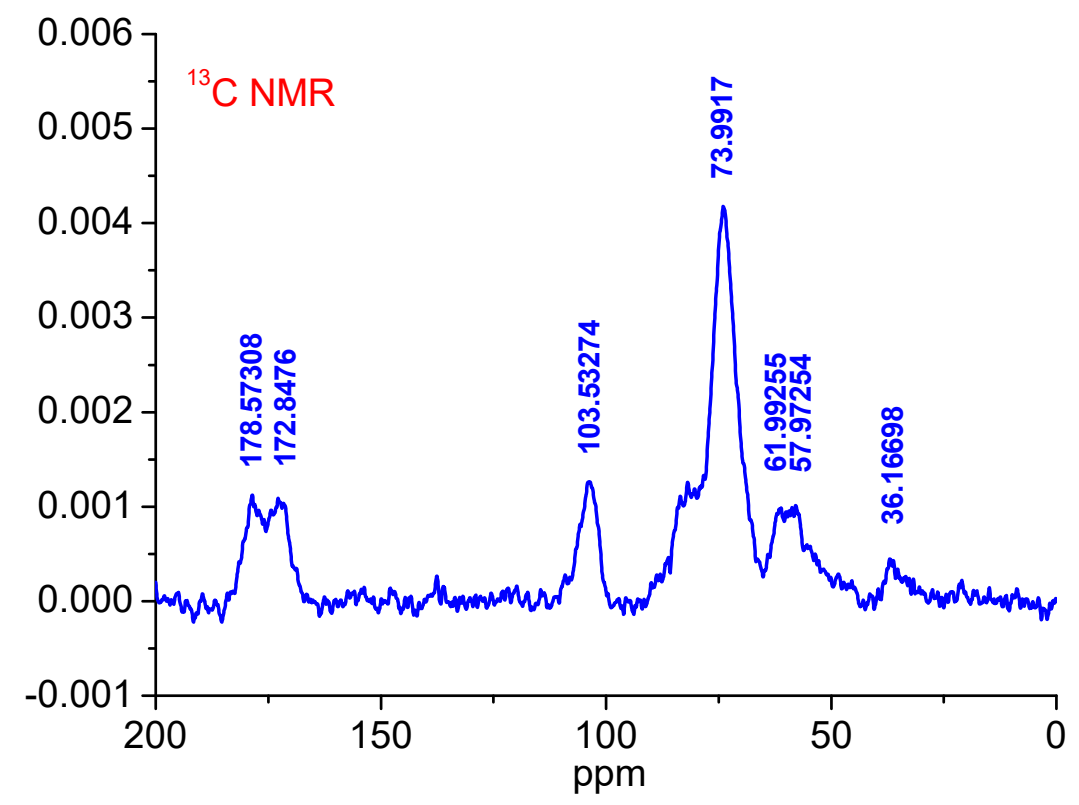


247 percentage of nitrogen was found for the introduction of amino carboxylic group into

248 cellulose. A minor portion of sulfur was found remained for result of the esterification

249 process.

250 Table 3

251 Elemental analysis data of adsorbent 4

\begin{tabular}{lll}
\hline Element & Found (\%) & Proposed structure (\%) \\
\hline $\mathrm{N}$ & 4.67 & 4.54 \\
$\mathrm{C}$ & 38.54 & 38.97 \\
$\mathrm{H}$ & 5.924 & 5.78 \\
$\mathrm{~S}$ & 0.466 & \\
\hline
\end{tabular}
analysis, A possible structure of material 4 was given in Fig.5. Its calculated values of the elemental analysis are listed in Table 3.

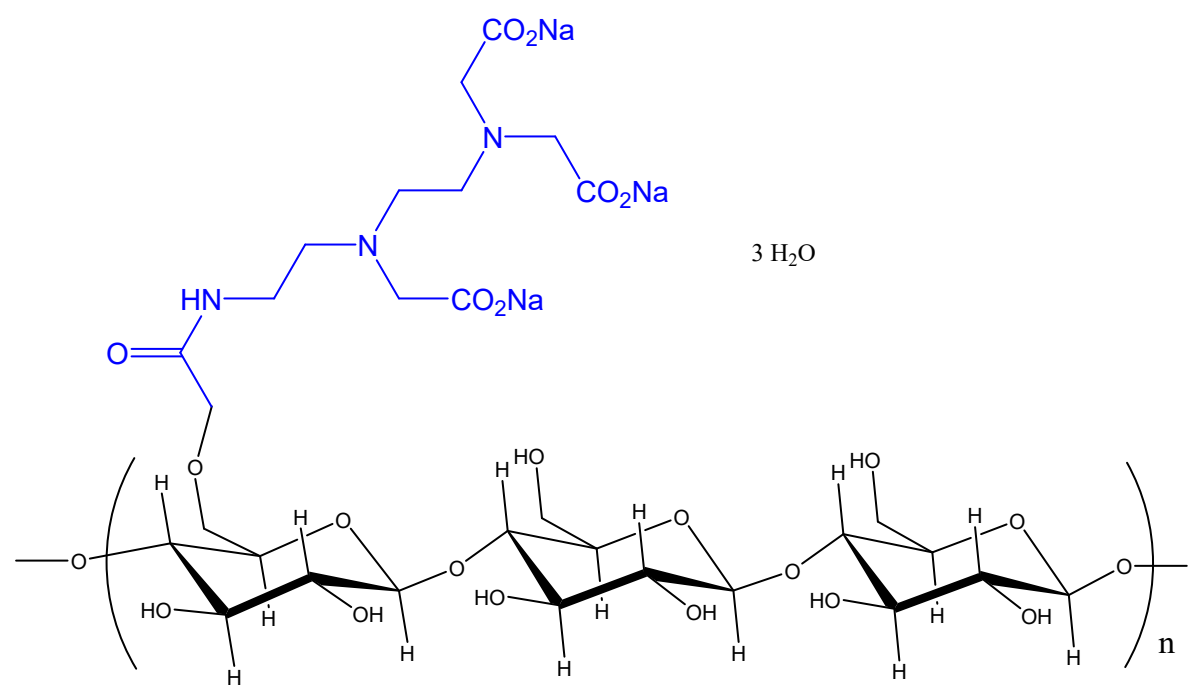

Fig.5. Proposed structure of the material 4 


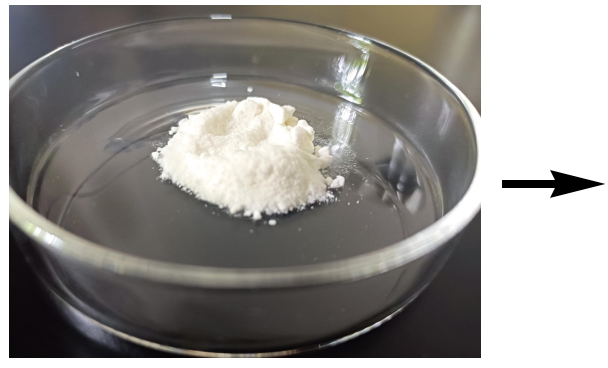

Adsorbent 4
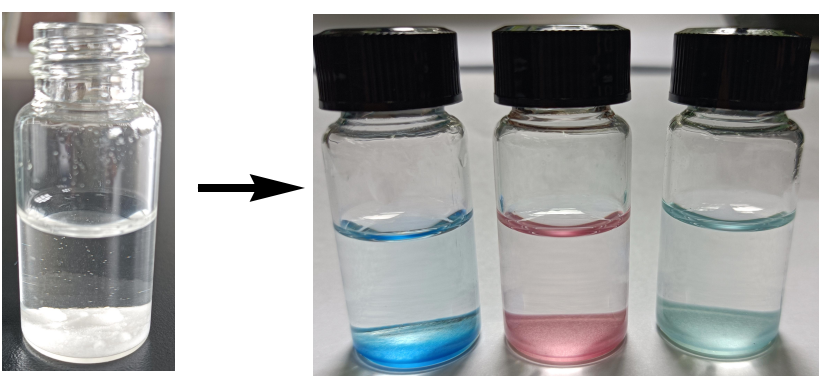

$\mathrm{Cu}^{2+} \quad \mathrm{Co}^{2+} \quad \mathrm{Ni}^{2+}$

Fig.6. Adsorbent 4 and color change after adsorption of $\mathrm{Cu}^{2+}, \mathrm{Co}^{2+}$ and $\mathrm{Ni}^{2+}$

Adsorption study of $\mathbf{4}$ to $\mathrm{Cu}^{2+}$ and $\mathrm{Pb}^{2+}$

Adsorption properties of the adsorbent 4 to target metal ions was studied. Conditions (Contact time and $\mathrm{pH}$ ) of the solution effect on adsorption were first carried out as functions of time and $\mathrm{pH}$.

Contact time effect on absorption

Contact time effect (kinetic study) of adsorbent $\mathbf{4}$ on adsorption $\mathrm{Cu}^{2+}$ and $\mathrm{Pb}^{2+}$ ions was showed in Fig.7. Time to reach the equilibrium was within $30 \mathrm{~min}$ for adsorption $\mathrm{Cu}^{2+}$ and $\mathrm{Pb}^{2+}$ ions. So, 30 min was used as contact time to study the effect of material 4 absorption with ions.
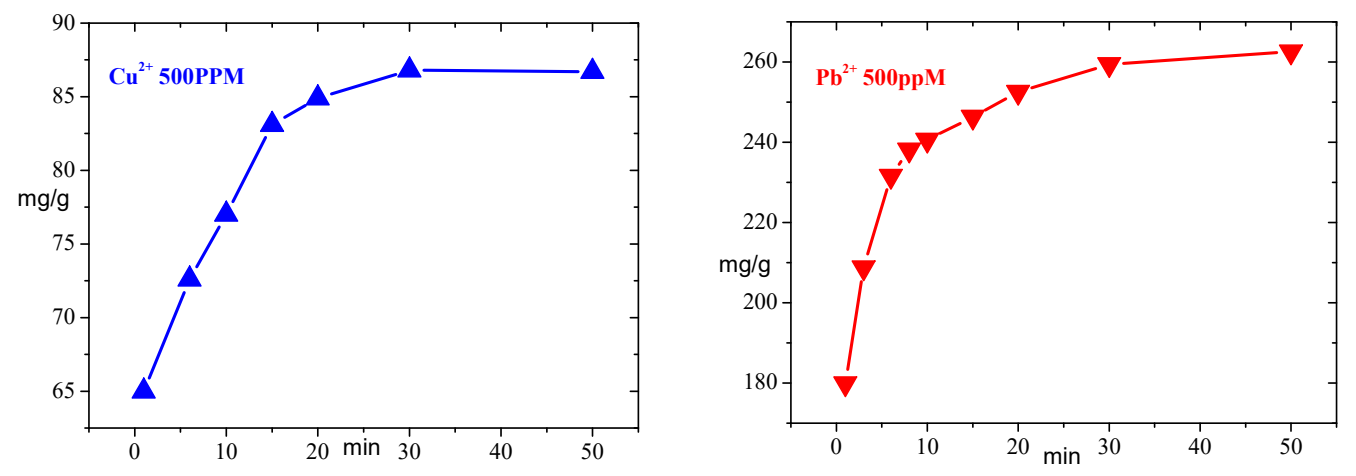

Fig.7. Contact time effect in adsorption of adsorbent $\mathbf{4}$ to metal ion 
282 Solution $\mathrm{pH}$ is a very important factor that affect on adsorbent for the removing metal 283 ions in water by adsorption, because it affects the proprotization of aminoacetic acid 284 groups, the ionization degree of chelating group and the type of adsorption functional group. The influence of the $\mathrm{pH}$ value on the adsorbent $\mathbf{4}$ for adsorption of metal ions was studied, and the contact time was 30min. As shown in Fig.8, when the pH value increases, the adsorption amount of metal ions by adsorbent 4 has a greater value. When the solution $\mathrm{pH}$ was 5 , the adsorbent observed a maximum adsorption amount on $\mathrm{Cu}^{2+}$ and $\mathrm{Pb}^{2+}$ ions, and $\mathrm{pH} 5$, not exceed the limit of hydrolysis of metal ions.
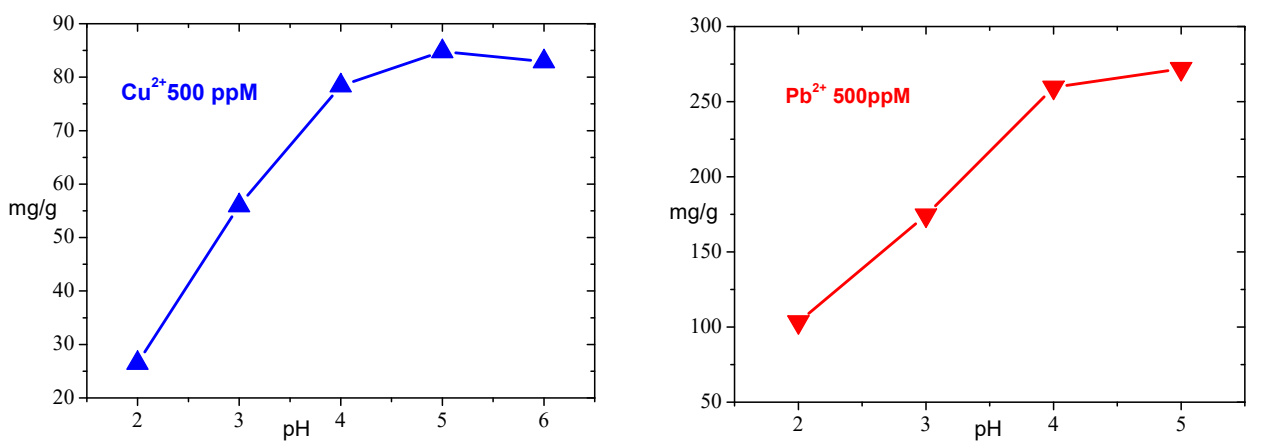

290

Fig.8. pH Effect of adsorbent 4 in adsorption of metal ion

Adsorption isotherms

Under optimal conditions included equilibrium time $30 \mathrm{~min}$ and $\mathrm{pH} 5.0$ for $\mathrm{Cu}^{2+}$ and $\mathrm{Pb}^{2+}$, adsorption experiments were carried out for evaluation of Langmuir (Eq. (1)) and Freundlich (Eq. (2)) isotherms (Ho et al. 2005; Osvaldo et al. 2007), that manifests function relationship between adsorption effect and the initial concentration of metal ions. The results are displayed in Fig.9 and Fig.10, and the data were listed in Table 4.

$$
\frac{c}{q}=\frac{1}{Q_{\max } \times b}+\frac{c}{Q_{\max }}
$$

$$
\ln q=\ln k+\frac{1}{n} \ln c
$$




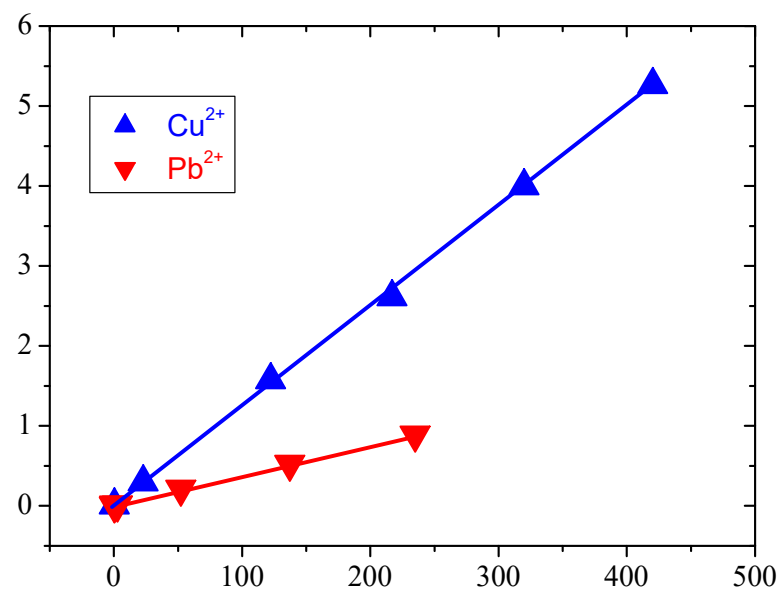

303

304

305

306

307

308

309

Fig. 9. The Langmuir isotherms of adsorbent 4

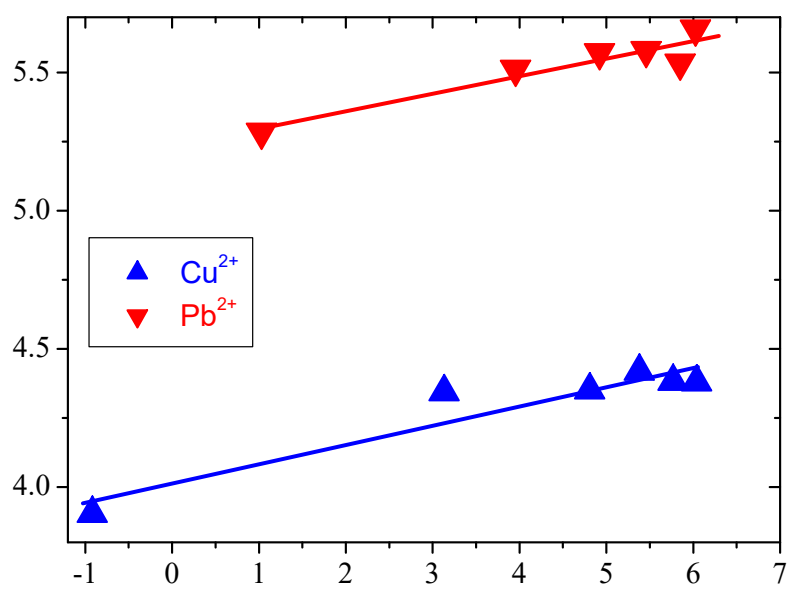

Fig. 10. The Freundlich isotherms of adsorbent 4

\section{Table 4}

The parameters in Langmuir and Freundlich equation

\begin{tabular}{lllllll}
\hline Metal ion & Langmuir & \multicolumn{5}{l}{ Freundlich } \\
\cline { 2 - 7 } & $\begin{array}{l}\boldsymbol{Q}_{\max } \\
(\mathrm{mg} / \mathrm{g})\end{array}$ & $\boldsymbol{b}$ & $\mathbf{R}^{2}$ & $\boldsymbol{k}$ & $\mathbf{n}$ & $\mathbf{R}^{2}$ \\
& 80.3 & 3.894 & 0.99946 & 55.45 & 14.351 & 0.89493 \\
& 266.7 & 0.509 & 0.99982 & 187.06 & 15.55 & 0.89834 \\
\hline $\mathrm{Cu}^{2+}$ & & & & & & \\
$\mathrm{Pb}^{2+}$ &
\end{tabular}

In Equation (1) and (2), $\boldsymbol{q}(\mathrm{mg} / \mathrm{g})$ is an amount of metal ions adsorbed by the unit

312 adsorbent, $\boldsymbol{c}(\mathrm{mg} / \mathrm{L})$ is the concentration of the remaining metal ion in the solution

313 when adsorption reaches equilibrium, $\boldsymbol{Q}_{\max }$ and $\boldsymbol{b}$ are parameters unique in Langmuir equation, and $\boldsymbol{k}$ and $\mathbf{n}$ are parameters unique in Freundlich equation. 
In Fig.9 and Fig.10, it can be seen that the data in the diagram are fitted by using Langmuir and Freundlich equations with good linear relations and high correlation coefficients, and thus the equations can be well used to explain the adsorption behavior of this adsorbent to metal ions

$\boldsymbol{Q}_{\max }$ in Langmuir isotherm equation is a parameter that manifests the largest adsorption capacity of adsorbent when the target metal ion in higher concentrated solution. In Table $\mathbf{4}$, It is clear that adsorbent $\mathbf{4}$ exhibits the maximum adsorption capacity for $\mathrm{Cu}^{2+}$ was $80.3 \mathrm{mg} / \mathrm{g}(1.264 \mathrm{mmol} / \mathrm{g})$, while adsorbs $\mathrm{Pb}^{2+}$ was $266.7 \mathrm{mg} / \mathrm{g}$ $(1.287 \mathrm{mmol} / \mathrm{g})$, and the maximum adsorption capacity of the two ions were almost the same in molar per gram. Parameter $\boldsymbol{b}$ manifests the bond energy in the coordination reaction between adsorbent and metal ion. Through the results listed Table 4, It can be concluded that adsorbent 4 shows a larger bond energy with $\mathrm{Cu}^{2+}$ than $\mathrm{Pb}^{2+}$, the possible explanation is that $\mathrm{Cu}$ belongs to transition metal and nitrogen atoms have a stronger bond with copper ions.

In Freundlich equation, parameter $\boldsymbol{k}$ is a index for adsorption capacity at the condition when metal ion concentration in equilibrium is unitary, and the case is 1 $\mathrm{mg} / \mathrm{L}$, features closer to the industrial wastewater. So that the parameter $\boldsymbol{k}$ could be used for adsorption capacity assessment of metal ions in contamined solutions diluted. The values of $k$ for $\mathrm{Cu}^{2+}$ was $55.45 \mathrm{mg} / \mathrm{g}(0.873 \mathrm{mmol} / \mathrm{g})$, and $187.06 \mathrm{mg} / \mathrm{g}(0.903$ $\mathrm{mmol} / \mathrm{g}$ ) for $\mathrm{Pb}^{2+}$, the values were almost the same when calculated into molar per gram. This indicates the adsorption superiority of adsorbent 4 when target metal ions in solution at very low concentrations.

These results were compared with a purchantable macroreticular adsorbent Duolite GT-73, which having thiol groups, reported by Vaughan et al (Vaughan et al, 2001). Duolite GT-73, the $\boldsymbol{Q}_{\max }$ of $\mathrm{Cu}^{2+}$ was $62 \mathrm{mg} / \mathrm{g}$ and $\mathrm{Pb}^{2+}$ was $122 \mathrm{mg} / \mathrm{g}$, respectively. The adsorbent 4 described in this paper exhibited double $\mathrm{Pb}^{2+} \boldsymbol{Q}_{\max }$ and higher $\mathrm{Cu}^{2+} \boldsymbol{Q}_{\max }$ than those of Duolite GT-73. 
Adsorbent 4 exhibited fast visible color change when adsorpted ions were $\mathrm{Cu}^{2+}, \mathrm{Co}^{2+}$ and $\mathrm{Ni}^{2+}$ et al, this was showed in Fig.6. According to the conditions obtained from $\mathrm{Pb}^{2+}$ and $\mathrm{Cu}^{2+}$, saturated adsorption capacity (mmol/g) were determined for $\mathrm{Ba}^{2+}$, $\mathrm{Mg}^{2+}, \mathrm{Mn}^{2+}, \mathrm{Co}^{2+}, \mathrm{Zn}^{2+}, \mathrm{Ni}^{2+}, \mathrm{Pb}^{2+}$ and $\mathrm{Cu}^{2+}$. The data was presented in Fig.11. The mininum adsorption capacity among them was $0.87 \mathrm{mmol} / \mathrm{g}$ for $\mathrm{Ba}^{2+}$. By comparing saturated adsorption capacity $(\mathrm{mmol} / \mathrm{g})$ of metal ions, the values differs each other at a rather low level, it could be concluded that there is fixed binding sites in adsorbent 4 and through which metal ions were adsorbed. In the adsorbent $\mathbf{4}$, the adsorption binding site was aminoacetic acid functions, It has similar features to the EDTA, and the results indicated that, the adsorbent $\mathbf{4}$ showed a good adsorption capacity to a wide range of metal ions.

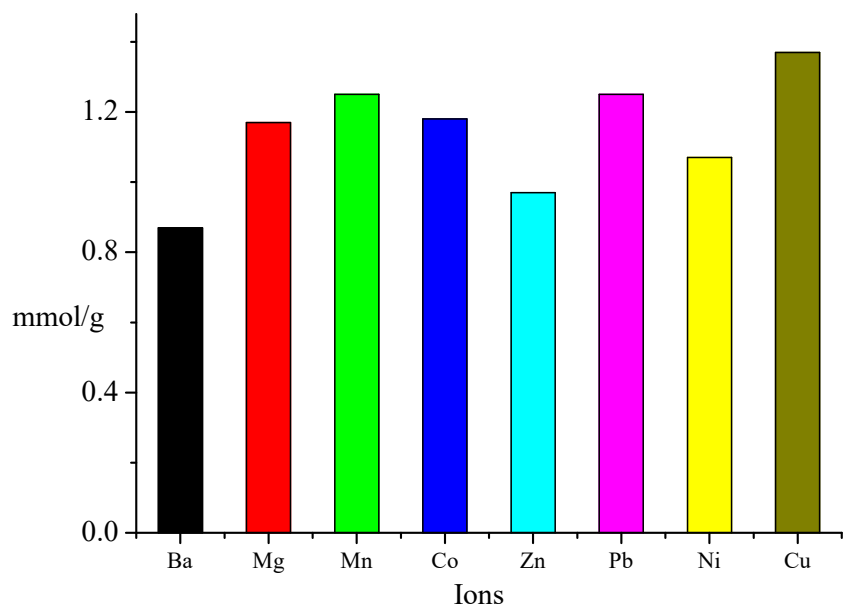

Fig.11. Adsorption capacity for $\mathrm{Ba}^{2+}, \mathrm{Mg}^{2+}, \mathrm{Mn}^{2+}, \mathrm{Co}^{2+}, \mathrm{Zn}^{2+}, \mathrm{Ni}^{2+}, \mathrm{Pb}^{2+}$ and $\mathrm{Cu}^{2+}$.

For a further comparing the adsorption properties of adsorbent 4 and EDTA, three different metal ions $\mathrm{Mg}^{2+}, \mathrm{Co}^{2+}$ and $\mathrm{Pb}^{2+}$ were selected as reference ions, and competitive ions adsorption experiments were conducted firstly. The data were presented in Fig.12, Fig.13 and Fig.14. 


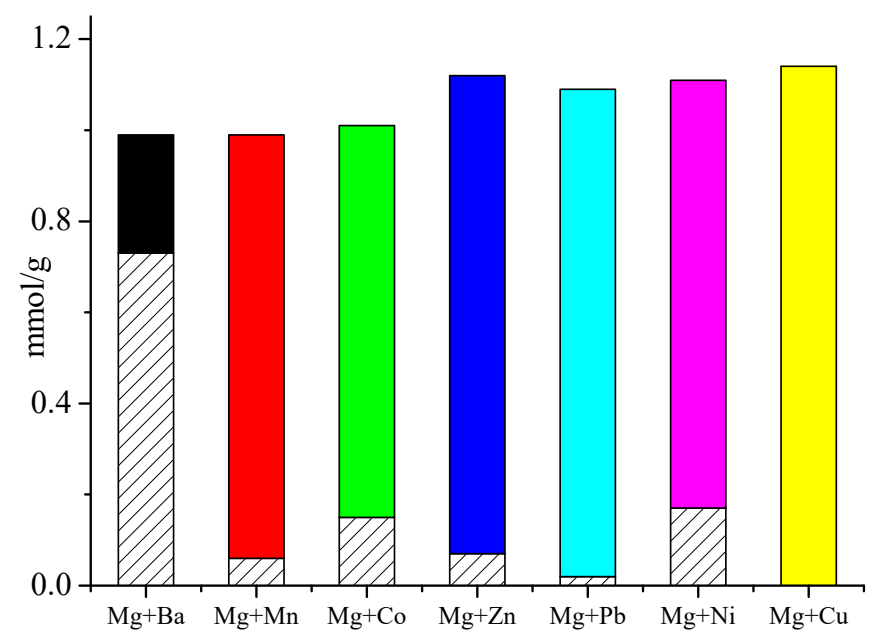

Fig.12. Competitive ions adsorption: $\mathrm{Mg}^{2+}+$ ions

In Fig.12, competitive ions adsorption was carried out between $\mathrm{Mg}^{2+}$ and other ions. In the competitive adsorption between $\mathrm{Mg}^{2+}$ and $\mathrm{Ba}^{2+}$, the adsorbent 4 showed a greater adsorption amount for $\mathrm{Mg}^{2+}$. Competitive ions adsorption between $\mathrm{Mg}^{2+}$ and other metal ions, the adsorbent 4 was more inclined to adsorb other metal ions, such as $\mathrm{Mn}^{2+}, \mathrm{Co}^{2+}, \mathrm{Zn}^{2+}, \mathrm{Pb}^{2+}$ and $\mathrm{Ni}^{2+}$. Few $\mathrm{Mg}^{2+}$ was absorbed in competitive adsorption with $\mathrm{Cu}^{2+}$.

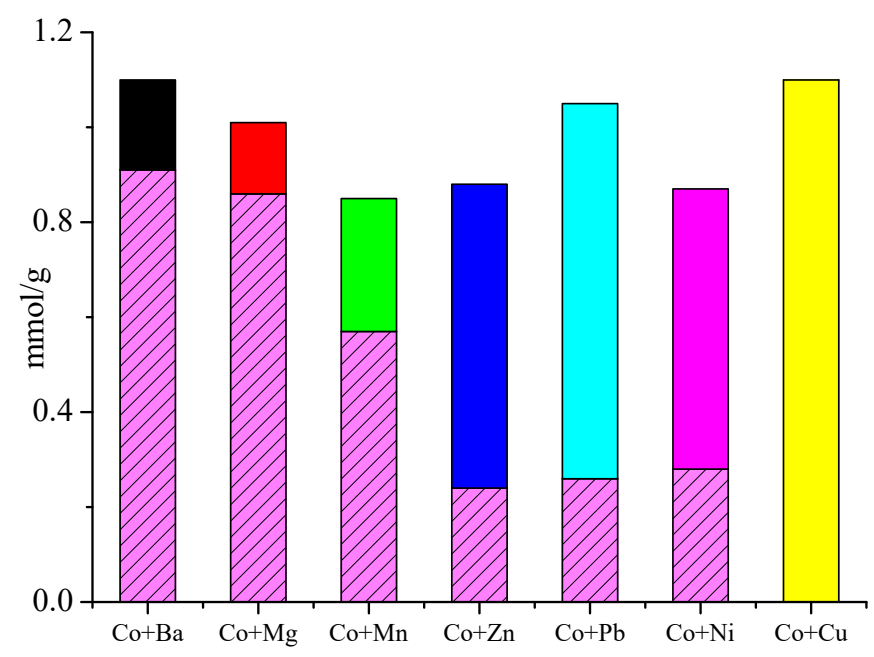

Fig.13. Competitive ions adsorption: $\mathrm{Co}^{2+}+$ ions

In Fig.13, competitive ions adsorption was conducted between $\mathrm{Co}^{2+}$ and other ions. In the competitive adsorption between $\mathrm{Co}^{2+}$ and $\mathrm{Ba}^{2+}, \mathrm{Mg}^{2+}$ and $\mathrm{Mn}^{2+}$, the 
adsorbent 4 showed a much larger adsorption amount for $\mathrm{Co}^{2+}$ in competition with $\mathrm{Ba}^{2+}$ and $\mathrm{Mg}^{2+}$, and a small larger amount than $\mathrm{Mn}^{2+}$. In the mixed solution of $\mathrm{Co}^{2+}$ with $\mathrm{Zn}^{2+}, \mathrm{Pb}^{2+}$ and $\mathrm{Ni}^{2+}$ respectively, the adsorbent 4 was more inclined to adsorb $\mathrm{Zn}^{2+}, \mathrm{Pb}^{2+}$ and $\mathrm{Ni}^{2+}$. Few $\mathrm{Co}^{2+}$ was absorbed in competitive adsorption with $\mathrm{Cu}^{2+}$.

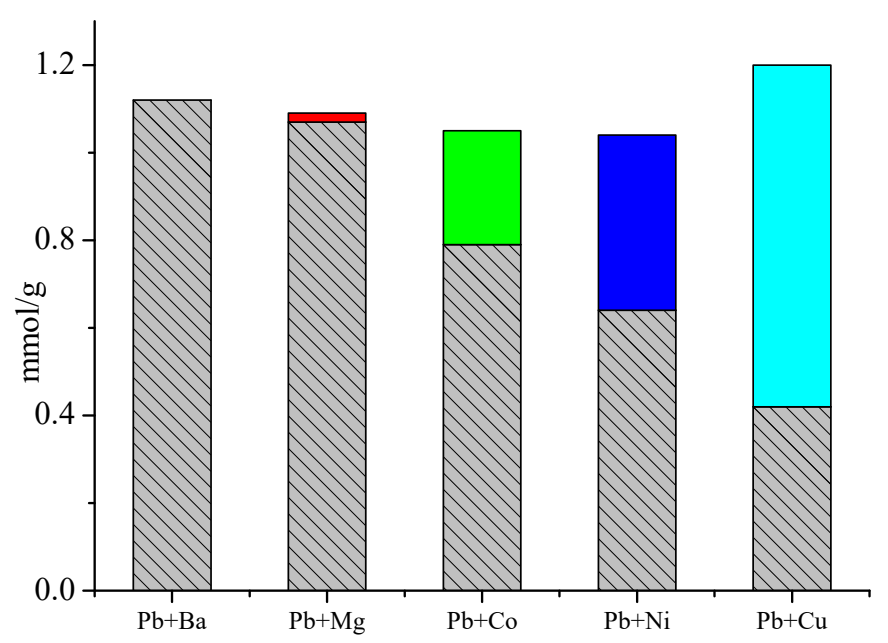

Fig.14. Competitive ions adsorption: $\mathrm{Pb}^{2+}+$ ions

In Fig.14, competitive ions adsorption was conducted between $\mathrm{Pb}^{2+}$ and other ions. The amount of metal ion adsorbed by adsorbent 4 vast majority was $\mathrm{Pb}^{2+}$ in the mixed solution of $\mathrm{Pb}^{2+}$ with $\mathrm{Ba}^{2+}, \mathrm{Mg}^{2+}$. In competitive ion adsorption between $\mathrm{Pb}^{2+}$ and $\mathrm{Co}^{2+}$ and $\mathrm{Ni}^{2+}$, the adsorbent 4 was inclined to adsorb $\mathrm{Pb}^{2+}$. Between $\mathrm{Pb}^{2+}$ and $\mathrm{Cu}^{2+}$, adsorbent 4 exhibited a larger adsorption amount for $\mathrm{Cu}^{2+}$, it was the evidence that adsorbent $\mathbf{4}$ shows a greater adsorption capacity for copper.

Table 5

The formation constant $\lg K(\mathrm{ML})$ of EDTA with metal ions

\begin{tabular}{lllllllll}
\hline ion & $\mathrm{Ba}$ & $\mathrm{Mg}$ & $\mathrm{Mn}$ & $\mathrm{Co}$ & $\mathrm{Zn}$ & $\mathrm{Pb}$ & $\mathrm{Ni}$ & $\mathrm{Cu}$ \\
\hline $\lg K(\mathrm{ML})$ with EDTA & 7.86 & 8.70 & 14.05 & 16.31 & 16.50 & 18.04 & 18.66 & 18.83 \\
\hline
\end{tabular}

Data from Ringbom A, Complexation in Analytical Chemistry, Interscience Publishers, NewYork,1963.

According to the results presented in Fig.12, Fig.13 and Fig.14, it could concluded that the adsorption behavior of the adsorbent 4 is similar to that of the EDTA, and the formation constant $\lg K(\mathrm{ML})$ of EDTA with ions were used to explain 
the adsorption behavior of adsorbent 4. From data listed in table 5, it could be seen that, among all metal ions, formation constant $\lg K(\mathrm{ML})$ of EDTA with $\mathrm{Ba}^{2+}, \mathrm{Mg}^{2+}$ are the much smaller, so in competitive ions adsorption experiments, the adsorbent 4 prefer to absorb other metal ions than $\mathrm{Ba}^{2+}$ and $\mathrm{Mg}^{2+}$. Formation constant $\lg K(\mathrm{ML})$ of EDTA with $\mathrm{Co}^{2+}$ is bigger than $\mathrm{Ba}^{2+}, \mathrm{Mg}^{2+}$ and $\mathrm{Mn}^{2+}$, thus the adsorbent 4 tends to adsorb $\mathrm{Co}^{2+}$ in competitive experiments. $\mathrm{Zn}^{2+}, \mathrm{Pb}^{2+}, \mathrm{Ni}^{2+}$ and $\mathrm{Cu}^{2+}$ have bigger $\lg K(\mathrm{ML})$ with EDTA than $\mathrm{Co}^{2+}$, so the adsorbent 4 tend to absorb these metal ions in competition adsorption. $\lg K(\mathrm{ML})$ of EDTA with $\mathrm{Ba}^{2+}$ and $\mathrm{Mg}^{2+}$ are much smaller than $\mathrm{Pb}^{2+}$, so the metal adsorbed mainly was $\mathrm{Pb}^{2+}$ in competitive ions adsorption. In the competition with $\mathrm{Co}^{2+}$ and $\mathrm{Ni}^{2+}$, the amount of $\mathrm{Pb}^{2+}$ adsorpted by adsorbent 4 were bigger. The $\lg K(\mathrm{ML})$ of EDTA with $\mathrm{Cu}^{2+}$ is slightly bigger than $\mathrm{Pb}^{2+}$, and therefore the amount of $\mathrm{Cu}^{2+}$ adsorpted is slightly greater than $\mathrm{Pb}^{2+}$.

\section{Conclusions}

A novel chelating material features like EDTA modified from cellulose was synthesized in situ for the first time, and thus, it was a new possible strategy for introducing chelating groups (aminoacetic acid) into the cellulose. Modified cellulose exhibited good adsorption capacity for a wide range of metal ions, such as $\mathrm{Ba}^{2+}, \mathrm{Mg}^{2+}$, $\mathrm{Mn}^{2+}, \mathrm{Co}^{2+}, \mathrm{Zn}^{2+}, \mathrm{Pb}^{2+}, \mathrm{Ni}^{2+}$ and $\mathrm{Cu}^{2+}$. Competitive ions adsorption experiments reveal its similar features of this adsorbent to EDTA, and it has potential use in the removal of heavy metal ion and recovery of useful ions from aqueous solution.

Acknowledgments We should grant our great thanks to Sichuan University of Arts and Sciences (2018SCL006Y, 2018SCL007Y and 2019BS012Z) and Science and Technology Burea of Dazhou city Sichuan Province (20YYJC0001) for financial supports.

Data listed in this paper are available in the mailbox of https://mail.126.com/ :

User Name: xiaoli_hu_sasu

Password: 15351243414 


\section{Compliance with ethical standards}

425

Conflict of Interest The authors declare that they have no known competing financial interests or personal relationships that could have appeared to influence the work reported in this paper.

\section{References}

Pereira TCB, et al (2016) Copper toxicology, oxidative stress and inflammation using zebrafish as experimental model. J. Appl. Toxicol 36: 876-885. http://dx.doi.org/10.1002/jat.3303

Bhalla V, Kumar R, Kumar M, Dhir A (2007) Bifunctional fluorescent thacalix[4]arene based chemo sensor for $\mathrm{Cu}^{2+}$ and $\mathrm{F}^{-}$ions. Tetrahedron 63: 11153-11159. http://dx.doi.org/10.1016/j.tet.2007.08.021

Mi HL, Stephen JL (2007) Metal-based turn-on fluorescent probes for sensing nitric oxide. Acc Chem Res 40:41-51. http://dx.doi.org/10.1021/ar950149t

Carver PL (2013) Metal Ions and Infectious Diseases. An Overview from the Clinic. Met. Ions Life Sci. 13:1-28. http://dx.doi.org/10.1007/978-94-007-7500-8_1

Kirsipuu T, et al (2020) Copper(II)-binding equilibria in human blood. Scientific reports 10(1):5686. http://dx.doi.org/10.1038/s41598-020-62560-4

Barakat MA (2011) New trends in removing heavy metals from industrial waste water. Arabiant Journal of Chemistry 4:361-377. http://dx.doi.org/10.1016/j.arabjc.2010.07.019

Xu C, et al (2014) Research Progress in Adsorption Performance of Heavy metal ion with Polyamine Chelating Adsorbents: a Review. Ion Exchange and Adsorption 30(1): 087-096. http://dx.doi.org/10.16026/j.cnki.iea.2014.01.003

Ghanshyam S, et al (2005) Synthesis, characterization and metal ion sorption studies of graft copolymers of cellulose with glycidyl methacrylate and some comonomers. Cellulose 12: 97-110. http://dx.doi.org/10.1007/s10570-004-2720-4

Hu MX, Xu PY, Wang LD, Liu YC (2016) Research Progress of Heavy Metal Ions Removal in Desulfurization Wastewater. Water Pollution and Treatment 4(3):85-90. http://dx.doi.org/10.12677/wpt.2016.43013 
Cao J, Fei DT, Tian XL, et al (2017) Novel modified micro crystalline cellulose-based porous material for fast and effective heavy-metal removal from aquous solution. Cellulose 24: 5565-5577. http://dx.doi.org/10.1007/s10570-017-1504-6

Gao X, Zhang H, Chen KL, et al (2018) Removal of heavy metal and sulfate ions by cellulose derivative-based biosorbents. Cellulose Published online. http://dx.doi.org/10.1007/s10570-018-1690-x

Nongbe MC, et al (2018) Cellulose paper grafted with polyamines as powerful adsorbent for heavy metals. Cellulose 25: 4043-4055. http://dx.doi.org/10.1007/s10570-018-1833-0

Lin XB, Jin JY, Guo XY, et al (2021) All-carboxymethyl cellulose sponges for removal of heavy metal ions. Cellulose 28: 3113-3122. http://dx.doi.org/10.1007/s10570-021-03685-1

Tsukinoki S, Yamada K, Itoh O, Nanbu N, Akama Y (2008) Solid Phase Extration of Cu, Ni and Co by EDTA Type Chelating Cellulose. The Japan Society for Analytical Chemistry 57:1033-1038. http://dx.doi.org/10.2116/bunsekikagaku.57.1033

Jilal I, Barkany SE, Bahari Z, Sundman O, Amhamdi H (2018) New quaternized cellulose based on hydroxyethyl cellulose (HEC) grafted EDTA: Synthesis, characterization and application for $\mathrm{Pb}$ (II) and $\mathrm{Cu}$ (II) removal. Carbohydrate Polymers 180:156-167. http://dx.doi.org/10.1016/j.carbpol.2017.10.012

Halluin MD, Barrull JR, Bretel G, Labrugère C, Grognec EL, Felpin FX (2017) Chemical Modified Cellulose Filter Paper for Heavy Metal Remediation in Water. ACS Sustainable Chem. Eng. 5:1965-1973. http://dx.doi.org/10.1021/acssuschemeng.6b02768

Singh AV, Singh R (2012) Synthesis,characterization and application of cellulose nitrilotricacetic acid (CNTAA) resin for removal of heavy metal ions from industrial effluent. J. Indian Chem. Soc. 89:77-84.

Huang Y, Yang C, Sun Z, Zeng G, He H (2015) Removal of cadmium and lead from aqueous solutions using nitrilotriacetic acid anhydride modified ligno-cellulosic material. RSC Adv. 5:11475. http://dx.doi.org/10.1039/C4RA14859B

Wilpiszewska K, Antosik AK, Schmidt B, Janik J, Rokicka J (2020) Hydrophilic Films Based on Carboxymethylated Derivatives of Starch and Cellulose. Polymers 12: 2447. http://dx.doi.org/10.3390/polym12112447

Ardiyanita PZ, Sutriyo S, Suryadi H (2020) Preparation and characterization of sodium 
carboxymethyl cellulose from kapok (Ceiba pentandra) alpha-cellulose. International Journal of Applied Pharmaceutics 12: 9-14. http://dx.doi.org/10.22159/ijap.2020.v12s1.25840

Hosangadi BD, Dave RH (1996) An Efficient General Method for Esterification of Aromatic Carboxylic Acids. Tetrahedron Letters 37:6375-6378. http://dx.doi.org/10.1016/0040-4039(96)01351-2

Osvaldo KJ, Gurgel LVA, Melo JCPD, Botaro VR, et al (2007) Adsorption of heavy metal ion from aqueous single metal solution by chemically modified sugarcane bagasse. Bioresource Technology 98:1291-1297. http://dx.doi.org/10.1016/j.biortech.2006.05.013

Ho YS, Chiu WT, Wang CC (2005) Regression analysis for the sorption isotherms of basic dyes on sugarcane dust. Bioresource Technology 96:1285-1291. http://dx.doi.org/10.1016/j.biortech.2004.10.021 using modified corncobs. Bioresource Technology 78:133-139. http://dx.doi.org/10.1016/S0960-8524(01)00007-4 